\title{
The Prevalence of Retinopathy in the Insulin-requiring Diabetic Patients of an English Country Town
}

\author{
B. K. McLEOD, J. R. THOMPSON and A. R. ROSENTHAL
}

Leicester

\begin{abstract}
Summary
A population-based survey of the insulin-requiring diabetics of a representative population was carried out. The overall prevalence of diabetes was 10.9/1000, that of insulin-requiring diabetes 4.1/1000. No retinopathy was found in $59 \%$, background retinopathy was found in $33 \%$ and proliferative and advanced disease in $8 \%$, diabetic maculopathy was present in $6.8 \%$ and the prevalence of potentially treatable disease undetected was $7.6 \%$. Significant risk factors identified for retinopathy were increased duration of diabetes and elevated diastolic blood pressure, those for maculopathy an increased age at examination and onset of diabetes and an elevated systolic blood pressure.
\end{abstract}

The care and treatment of diabetic patients form a significant and important part of the workload of ophthalmic departments and there are indications that this workload will increase. Appropriate retinal photocoagulation is established as being effective in preventing visual loss. ${ }^{1,2,3}$ The main necessities are the detection of those at risk and the provision of adequate treatment. Planning for manpower and resources requires a knowledge of the problem and information has been provided by surveys in the United Kingdom which have been carried out, mainly at specialised hospital clinics.

In an attempt to contribute to this knowledge we have carried out a populationbased survey of eye disease in the insulinrequiring patients of an English town. The results from the survey have been used to estimate the prevalence of diabetic retinopathy and to examine the relationship between retinopathy and five potential risk factors, viz. age at examination, age at onset, duration of diabetes, systolic blood pressure and degree of diabetic control.

\section{Method}

\section{Population}

The population chosen for this survey was that of Melton Mowbray, a country town in Leicestershire. An unusual situation exists there in that virtually all of the town and most of the surrounding district is served by a single twelve-doctor practice working from the same premises. The population is geographically well defined and has been shown to be demographically representative of that of England and Wales. ${ }^{4}$ A computerised age-sex register of the entire population registered with the practice (approx 32,000) has been established by the Leicester University Department of Community Health. The diabetic patients were identified from the records of prescriptions for insulin and other hypoglycaemic agents, together with prescriptions for blood and urine testing kits.

The insulin-requiring patients known to the practice on January 1st 1987 were contacted and offered an ophthalmic 
examination at the Melton Mowbray War Memorial Hospital or at home if a visit to the clinic was not possible.

\section{Examination}

The patients who agreed to be seen were all interviewed between January 1987 and December 1987 using a pre-prepared questionnaire to record basic information regarding both their diabetic and general medical histories.

The examination, carried out by an ophthalmologist and an optician, consisted of:-

(a) a full ophthalmic refraction and recording of the best corrected visual acuity measured by Snellen chart at six metres.

(b) the measurement of the intra-ocular pressure with a Perkins hand-held tonometer in both the sitting and supine positions.

(c) the measurement of the systolic blood pressure, both supine and standing, with a Copal U-231 Automatic Sphygmomanometer which has been shown to be accurate and useful for epidemiological studies. ${ }^{5}$

(d) slit lamp examination of the anterior segments.

(e) after maximum mydriasis, a retinal examination carried out with the direct and indirect ophthalmoscope to record the presence or absence of background retinopathy, diabetic maculopathy, proliferative retinopathy, vitreous haemorrhage or advanced diabetic eye disease such as traction retinal detachment.

(f) stereo fundus photographs of seven standard thirty degree retinal fields were taken with a Zeiss fundus camera.

(g) Venous blood was taken for the measurement of glycosylated haemoglobin $\left(\mathrm{Hb} \mathrm{A}_{1}\right)$ to estimate the degree of diabetic control over the four to eight weeks prior to examination.

\section{Grading of fundus photographs}

The scheme adopted for grading of the retinal photographs was that used by the Wisconsin Epidemiological Survey of
Table 1 Summary of scheme used for photographic grading

$\begin{array}{ll}\text { Retinography grades } \\ 1 & \text { no retinopathy } \\ 1.5-5 & \text { background retinopathy } \\ 6 & \text { fibrous proliferation } \\ 6.1 & \text { photocoagulation burns } \\ 6.5-7 & \text { proliferative retinopathy } \\ 8 & \text { advanced disease }\end{array}$

Table II Age-specific prevalence rates of insulinrequiring diabetics

\begin{tabular}{lrrrc}
\hline Age (yrs) & Male & Female & Total & $\begin{array}{c}\text { Prevalence } \\
\text { (per 1000) }\end{array}$ \\
\hline $0-19$ & 7 & 4 & 11 & 1.1 \\
$20-39$ & 20 & 17 & 37 & 3.9 \\
$40-59$ & 21 & 16 & 37 & 5.0 \\
$60+$ & 26 & 20 & 46 & 7.0 \\
Total & 74 & 57 & 131 & 4.1 \\
\hline
\end{tabular}

Diabetic Retinopathy summarised in Table I. ${ }^{6}$ In this scheme the stereo slide pairs of each retinal field is examined for diabetic retinopathy and a grade of severity determined by comparison with a set of standard slides. ${ }^{?}$

The highest (i.e. worst) field grade of each eye was taken as the overall grade for that eye. The grading was carried out in a masked fashion after an initial inspection of the slide sets to ensure their quality. A second grading was carried out at a later stage and if the gradings did not concur then a further, independent grader was used, and a final grade agreed upon. This method of grading the slides was used because it was found to give a reproduceable, overall retinopathy grade for each eye.

In addition to this overall grading, the presence of diabetic maculopathy was recorded separately. The criteria of The Early Treatment Diabetic Retinopathy Survey $^{3}$ were used, namely, the presence of discrete macular oedema or hard exudates within one disc diameter of the centre of the macula. Evidence of focal macular photocoagulation, presumed to have been directed at diabetic maculopathy, was recorded as treated maculopathy. 


\section{Statistical analysis}

The differences between the means were tested using one way analysis of variance and the $t$ test. Risk factors for retinopathy were assessed using a multinomial version of logistic regression known as proportional odds regression ${ }^{8}$ and the same risk factors were assessed for maculopathy by logistic regression.

\section{Results}

One hundred and thirty one insulin-requiring patients were identified from the practice records (4.1 per thousand) and two hundred and nineteen non insulin-requiring diabetic patients (6.8 per thousand). The overall prevalence rate of diabetes was thus 10.9 per thousand in this population.

The mean age of the insulin-requiring patients was 48 yrs (range 6-81), 74 (57.9\%) were males and $57(42.1 \%)$ were females. The mean age at diagnosis of diabetes was 33 years (range 1-69 yrs) and the mean duration of diabetes was 15 yrs (range 1-52 years). The age-specific prevalence rates are shown in Table II. Of this total of 131 patients, 113 $(86 \%)$ agreed to an ophthalmic examination. Relevant details of the attenders and nonattenders are summarised in Table III. The non attenders were younger $(\mathrm{p}<0.01)$ but there was no significant difference in the age at diagnosis $(p=0.09)$ or duration $(p=0.1)$ of diabetes. We were unable to grade seventeen of the patients examined by the photographic method, only a clinical grading was possible. This was either because they had been examined at home where it was not feasible to carry out fundus photography, or that the photographs taken were not of a high enough quality to allow for accurate grading. There was no statistical difference for age at examination, age at diagnosis and duration of diabetes for those with and without photographic grades.

Thirty four patients $(30 \%)$ regularly attended a hospital ophthalmic clinic and fifteen $(13.2 \%)$ had been treated with laser photocoagulation. In addition another three patients had undergone fluorescein angiography but had not required treatment.

\section{Photographic grades of retinopathy}

The age-specific prevalence of retinopathy levels for each eye graded photographically is shown in Table IV and by duration of diabetes in Table $\mathrm{V}$.

One hundred and ninety one eyes of 96 patients were graded in this way. No retinopathy (photo. grade 1) was present in fifty one (left) and fifty (right) eyes, a total of one hundred and one eyes (53\%). Background retinopathy (photo grades 1.5-5) was found in thirty six (left) and thirty seven (right) eyes, a total of seventy three eyes $(38 \%)$.

Severe retinopathy, or eyes ungradable due to diabetic eye disease (photo grades 6-8) was found in nine (left) and eight (right) eyes, a total of seventeen eyes $(9 \%)$.

Looking at the results in terms of the grading per individual patient then the following results were obtained (Table VI):-

(1) The patients having no evidence of diabetic retinopathy in either eye $(n=47$; $50 \%$ ) had a mean age of 46 yrs (range 1379) and the mean duration of diabetes

Table III Relevant details of attenders and non-attenders

$P G=$ Photographed group

$N P G=$ Non photographed group

\begin{tabular}{|c|c|c|c|c|}
\hline & No. & Mean Age & $\begin{array}{c}\text { Mean Age } \\
\quad \text { at } \\
\text { Diagnosis }\end{array}$ & $\begin{array}{c}\text { Mean } \\
\text { Duration }\end{array}$ \\
\hline Attenders & $\left.\begin{array}{l}\text { PG 96 } \\
\text { NPG17 }\end{array}\right\} 113$ & $\begin{array}{l}50 \\
47\end{array}$ & $\begin{array}{l}33 \\
29\end{array}$ & $\begin{array}{l}17 \\
18\end{array}$ \\
\hline $\begin{array}{l}\text { Non- } \\
\text { attenders }\end{array}$ & 18 & $36^{*}$ & 25 & $\begin{array}{c}11 \\
* \mathrm{p}<0.01\end{array}$ \\
\hline
\end{tabular}


was 10 yrs (range 0-29). The mean age at diagnosis of diabetes was 36 yrs (range 164)

(2) Those with background retinopathy in one or both eyes $(n=39)(41 \%)$ had a mean age of 51 years (range 21-81) and the mean duration of diabetes was 21 years (range 1-57). The mean age at diagnosis was 30 years (range 9-64).

(3) Those with proliferative or advanced diabetic eye disease in one or both eyes $(n=10 ; 9 \%)$ had a mean age of 52 years (range 26-71) and the mean duration of diabetes was 24 years (range 13-51). Mean age at diagnosis of diabetes in these patients was 28 years (range 9-50). One of this group was considered to have

Table IV Age-specific photographic grades of retinopathy

\begin{tabular}{lrrrrrrrrr}
\hline & \multicolumn{1}{c}{ Retinography grades } \\
Age (yrs) & 1 & 1.5 & 2 & 3 & 4 & 6 & 6.1 & 6.5 & 8 \\
\hline $0-19$ & 10 & - & - & - & - & - & - & - & - \\
$20-39$ & 32 & 1 & 5 & 8 & 1 & - & 2 & 1 & - \\
$40-59$ & 29 & - & 7 & 13 & 4 & - & 4 & - & - \\
$60+$ & 30 & 4 & 4 & 22 & 4 & 1 & 4 & - & 5 \\
Total & 101 & 5 & 16 & 43 & 9 & 1 & 10 & 1 & 5 \\
\hline
\end{tabular}

Table V Retinography grades related to duration of diabetes

\begin{tabular}{lrrrrrrrrrr}
\hline $\begin{array}{l}\text { Duration } \\
\text { Diabetes } \\
\text { (yrs) }\end{array}$ & 1 & 1.5 & 2 & 3 & 4 & 6 & 6.1 & 6.5 & 8 \\
\hline $0-9$ & 55 & - & 2 & 5 & 5 & - & - & - & - \\
$10-19$ & 28 & 1 & 5 & 14 & 2 & - & 2 & - & 1 \\
$20-29$ & 12 & 3 & 6 & 19 & 2 & - & 6 & - & 1 \\
$30+$ & 6 & 1 & 3 & 5 & - & 1 & 2 & 1 & 3 \\
Total & 101 & 5 & 16 & 43 & 9 & 1 & 10 & 1 & 5 \\
\hline
\end{tabular}

untreated proliferative disease and referral for further assessment was recommended.

\section{Photographic grades of Maculopathy}

In addition to the overall grading of retinopathy the separate grading for the presence of maculopathy revealed the following results:-

(1) seven patients $(6.0 \%)$ had undergone focal photocoagulation to the macular region for presumed diabetic maculopathy. The mean age of this group was 57 years (range 41-66), the mean duration of diabetes was 20 years and mean age at onset of 37 years.

(2) a further nine patients (8\%) had untreated maculopathy and it was recommended they should be referred for evaluation. The mean age of this group was 53 years (range 22-67) the mean duration of diabetes of 17 years and the mean age at onset 36 years

\section{Additional information}

Photographic grades were not available in thirty five patients but the following information was obtained:-

(1) of the seventeen seen but not graded photographically four were found clinically to have background retinopathy.

(2) the practice records showed that one of the eighteen non-attenders was blind from advanced diabetic disease but no other ophthalmic problem was documented in this group.

\section{Overall prevalence of retinal disease}

By incorporating this additional information a total estimate of the prevalence of diabetic

Table VI Number of patients with Grade 1 (no retinopathy) Grades 1.5-5 (background retinopathy) and Grades 6-8 (proliferative or advanced retinopathy)

\begin{tabular}{lccccc}
\hline $\begin{array}{l}\text { Retinopathy } \\
\text { grade }\end{array}$ & No. & $\%$ & Mean age & $\begin{array}{c}\text { Mean age at } \\
\text { Diagnosis }\end{array}$ & $\begin{array}{c}\text { Mean } \\
\text { Duration }\end{array}$ \\
\hline 1 & 47 & 50 & 46 & 36 & 10 \\
$1.5-5$ & 39 & 41 & 51 & 30 & 21 \\
$6-8$ & 10 & 9 & 52 & 28 & 24 \\
\hline
\end{tabular}


retinopathy in the 131 insulin-requiring diabetic patients may be obtained:-
(1) No retinopathy $59 \%$
(2) background retinopathy $33 \%$
(3) significant or serious diabetic eye disease
(4) maculopathy $8 \%$ $6.8 \%$

Undetected, potentially treatable, retinal disease was found in $7.6 \%$, one of the patients having proliferative disease and nine diabetic maculopathy.

\section{Visual acuity}

Two patients, aged 63 years and 77 years were blind and this represents $1.5 \%$ blind registration as the result of diabetic retinopathy. Four patients $(3 \%)$ had acuities of less than $6 / 24$ in either eye due to diabetic retinal disease and a further five $(3.8 \%)$ only finger counting vision in one eye, three due to diabetic retinal disease and two due to cataract. Fifty eight patients $(51 \%)$ had acuities of $6 / 6$ or better in both eyes.

\section{Risk factors}

The potential risk factors examined are shown in Table VII. They were assessed for three broad categories of retinopathy, namely, no retinopathy, background retinopathy, proliferative and advanced disease. The most significant risk factor found for severity of retinopathy from these data was a longer duration of diabetes $(p<0.0001)$. Elevated diastolic blood pressure and higher age at examination also being shown to be significant $(p<0.05)$ (Table VIII). On further analysis, when it was assumed that duration of diabetes was known the most important additional risk factor was found to be elevated diastolic blood pressure (Table IX).

The same set of potential risk factors were evaluated for maculopathy. A higher age at the time of examination and at diagnosis $(p<0.01)$, and elevated systolic blood pressure $(\mathrm{p}<0.05)$ were the three risk factors that were statistically significant (Table X).

\section{Discussion}

The patients studied in this survey were identified from a population in which the prevalence rate of diabetes was 10.9 per
Table VII

\begin{tabular}{lccc}
\hline & \multicolumn{3}{c}{ Risk factors considered } \\
Factor & Units & Mean & Range \\
\hline Systolic BP & mmHg & 153 & $99-249$ \\
Diastolic BP & mmHg & 83 & $52-103$ \\
Age & yrs & 49 & $13-79$ \\
Age at Diagnosis & yrs & 33 & $1-69$ \\
Duration & yrs & 16 & $0-52$ \\
Glycosylated & $\%$ & 8.9 & $4.1-17.3$ \\
Haemoglobin & & & \\
\hline
\end{tabular}

Table VIII Risk factors considered for retinopathy

\begin{tabular}{|c|c|c|}
\hline Risk factor & \multicolumn{2}{|c|}{$\begin{array}{l}\text { Retinopathy I } \\
\text { Drop in }\end{array}$} \\
\hline Systolic BP & 1.0 & ns \\
\hline Diastolic BP & 6.4 & $\mathrm{p}<0.05$ \\
\hline Age & 6.4 & $\mathrm{p}<0.05$ \\
\hline Age at Diagnosis & 1.0 & ns \\
\hline Duration Diabetes & 28.4 & $0<0.0001$ \\
\hline Glycosylated & 0.1 & ns \\
\hline Haemoglobin & & \\
\hline
\end{tabular}

Table IX Risk factors considered for retinopathy assuming duration known

\begin{tabular}{|c|c|c|}
\hline Risk factor & $\begin{array}{l}\text { Retinop } \\
\text { Drop in } \\
\text { deviance }\end{array}$ & p-value \\
\hline Systolic BP & 0.5 & ns \\
\hline Diastolic BP & 6.4 & $\mathrm{p}<0.05$ \\
\hline Age & 0.5 & ns \\
\hline Age at Diagnosis & 0.5 & ns \\
\hline Glycosylated & 0.2 & ns \\
\hline Haemoglobin & & \\
\hline
\end{tabular}

Table X

\begin{tabular}{lcl}
\hline Risk factor & $\begin{array}{c}\text { Retinopathy II } \\
\text { Drop in } \\
\text { deviance }\end{array}$ & $\mathrm{p}$-value \\
\hline Systolic BP & 5.0 & $\mathrm{p}<0.05$ \\
Diastolic BP & 2.4 & $\mathrm{~ns}$ \\
Age & 9.9 & $\mathrm{p}<0.01$ \\
Age at diagnosis & 8.6 & $\mathrm{p}<0.01$ \\
Duration & 0.0 & $\mathrm{~ns}$ \\
Glycosylated & 0.7 & $\mathrm{~ns}$ \\
Haemoglobin & & \\
\hline
\end{tabular}


thousand, very similar to the United Kingdom prevalence of about 10 per thousand suggested by West. ${ }^{(9)}$ The response rate for the survey was $86 \%$. The nonresponders tended to be younger and included some students living away from home, and patients who felt that enough of their time was already being spent in the control of their disease. The practice records showed that all but one had no documented eye problems.

Direct comparisons between surveys of the ophthalmic problems of diabetic patients are not always possible. For example those surveyed in special hospital clinics are a preselected group, in-some studies only specific age-groups have been examined and definitions for diabetes and grading of ocular findings vary. In addition the prevalence rate for diabetes varies in different cultures as do criteria for blind registration. Caird et al ${ }^{10}$ calculated from the figures of Sorsby ${ }^{11}$ that about $2 \%$ of diabetics in England and Wales were blind from retinopathy. This is probably a minimum figure and would certainly underestimate the number handicapped by reduced vision but not eligible for blind registration. This is indicated by the fact that in this survey $1.5 \%$ were registered blind but an overall figure for visual disability of $8.3 \%$ was found.

The overall prevalence of diabetic retinopathy of any sort was $41 \%$ in this study, with $33 \%$ having background and $8 \%$ significant or severe disease. This is lower than that reported by Sjolie ${ }^{12}$ in a study of a Danish population, when an overall occurrence of $77 \%$ for men and $74 \%$ for women was found. Nilssonn ${ }^{13}$ found prevalence rates of $40 \%$ background and $15 \%$ proliferative retinopathy in another Danish population. The Wisconsin ${ }^{6}$ survey of those diagnosed diabetic before the age of 30 years found an overall prevalence rate of $71 \%$ with retinopathy in those with diabetes for less than five years and $97.5 \%$ in those diabetic for 15 years or more. Grey et $\mathrm{al}^{14}$ in a survey of an English diabetic clinic found retinopathy to be present in $43.4 \%$ of insulin dependent diabetics studied and sight threatening retinopathy in $13.3 \%$ of eyes of those studied.
That the prevalence and severity of retinopathy increases with duration of diabetes is well established ${ }^{15,16}$, and the results of this survey are in accord with this finding. A small number of those diabetic for less than ten years had background retinopathy whilst those who had undergone pan-photocoagulation had a duration of at least ten or more years and severe disease was found predominantly in those with a duration of twenty or more years.

Elevated diastolic blood pressure was found to be an additional risk factor for retinopathy and a significant association between blood pressure and degree of retinopathy has been found in other studies. ${ }^{17,18}$ The Wisconsin study ${ }^{6}$ found higher diastolic blood pressure to be significantly related to the presence and severity of retinopathy in younger-onset insulin taking patients and systolic blood pressure in older onset diabetic patients. Although both hypertension and retinopathy may be the independent result of diabetic microvascular disease enough evidence seems to exist to suggest that good hypertensive control is a worthwhile aim in an attempt to limit retinopathy.

No significant association was found in this study between recent diabetic control, as measured by the level of glycosylated haemoglobin, and the prevalence and severity of retinopathy. However it would be incorrect to draw conclusions from this result as a single measure of the control over the weeks preceding examination in no way indicates the degree over the preceding years. Studies have shown that good diabetic control has a beneficial effect on retinopathy. ${ }^{1}$ Bradley and Rames ${ }^{19}$ found that in juvenile diabetics followed for 20-40 years $7 \%$ with good control, $19 \%$ with fair control and $43 \%$ with poor control had marked or extreme retinopathy. Animal experiments have added weight to the general impression that good metabolic control is desirable with regard to retinopathy. In a trial with dogs Engerman ${ }^{20}$ found that good diabetic control resulted in less retinopathy and that the response of the retinal vasculature was influenced by the previous degree of control. 
Potentially treatable retinal disease was undetected in $7.6 \%$ of those studied and all but one of these had maculopathy. The prevalence of diabetic maculopathy was high in this insulin-requiring population in view of its traditional association with the non insulin-dependent type. ${ }^{21} \mathrm{~A}$ higher age at examination and at diagnosis were the two most significant risk factors and the mean age at examination of 53 years and age at diagnosis of 36 years shows that they belong to the older-onset group of diabetics. Duration of diabetes was not found to be a significant factor in the development of maculopathy. but diabetes of the older-onset type is known to have a long pre-clinical phase and its precise duration difficult to define. In this survey no potentially treatable retinopathy was found in those having diabetes for less than ten years and examination within this time would be prudent for those with diabetes of the younger-onset type. However the olderonset type insulin-requiring patients may have significant disease at diagnosis and ophthalmic examinations should be carried out soon afterwards.

This study would not have been possible without the help and cooperation of the Medical Practitioners of Latham House, and the War Memorial Hospital, Melton Mowbray. We are grateful to Dr. T. Smith for the background and field work and Professor Michael Clarke and staff of the Department of Community Health for guidance and advice. The support of the Anne Allerton Fund is acknowledged.

\section{References}

${ }^{1}$ Diabetic Retinopathy Research Group. Preliminary reports on the effects of photocoagulation therapy. Am J Ophthalmol 1976, 81: 383-96.

2 Townsend C, Bailey J, Kohner E: Xenon arc photocoagulation for the treatment of diabetic maculopathy. Br J Ophthalmol 1980, 64: 38591.

${ }^{3}$ Early Treatment Diabetic Retinopathy Study Research Group. Early Treatment Diabetic Study Report No 1. Photocoagulation for diabetic macular oedema. Arch Ophthalmol 1985, 103: 1796-806.

${ }^{4}$ Clarke M, Clarke S, Odell A: The Elderly at home: health and social status. Health Trends 1984, 16: 3-7.

${ }^{5}$ Gallacher J, Yarnell J, Rogers S, Sweetman P: Automatic measurement of blood pressure: evaluation of the Copal UA-231 Automatic Sphygmomanometer. J Epidemiol and Comm Health 1985, 39: 220-3.

${ }^{6}$ Klein R, Klein BEK, Moss ES, et al: The Wisconsin Epidemiological Study of Diabetic Retinopathy. II. Prevalence and risk of diabetic retinopathy when age at diagnosis is less than 30 years. Arch Ophthalmol 1984, 102: $520-6$.

${ }^{7}$ A modification of the Airlie House Classification of Diabetic Retinopathy. Diabetic Retinopathy Study Research Group. Report No. 7. Invest Ophthalmol Vis Sci 1981, 21: 210-26.

${ }^{8}$ McCullagh P: Regression models for ordinal data. J Roy Stat Soc 1980, B42: 109-42.

${ }^{9}$ West KM. Epidemiology of Diabetes and its vascular lesions. New York: Elsevier, 1978, 89-91.

${ }^{10}$ Caird F, Pirie A, Ramsell T: Diabetes and the Eye. Oxford: Blackwell Scientific Publications 1969, 127-128.

${ }^{11}$ Sorsby A: The incidence and cause of blindness in England and Wales 1948-1962. Reports on Public Health and Medical Subjects. No 114, 1966. H.M.S.O. London.

${ }^{12}$ Sjolie A: Ocular complications of insulin treated diabetes melitus. An epidemiological study. Acta Ophthalmol 1985, 63: Suppl 172:29.

${ }^{13}$ Nilsson S, Nilson J et al: The Kristianstad survey II. Acta Med Scand 1967, Suppl 469: 1-42.

${ }^{14}$ Grey R, Malcolm N: Ophthalmic survey of a diabetic clinic I. Br J Ophthalmol 1986, 70: 797-803.

${ }^{15}$ Burditt A, Caird F: The natural history of diabetic retinopathy. Quart J Med 1968, 37: 303-17.

${ }^{16}$ Kahn H, Bradley R: Prevalence of diabetic retinopathy. Br J Ophthalmol 1975, 59: 345-9.

${ }^{17}$ Kornerup T: Studies in diabetic retinopathy. Acta Med Scand 1955, 153: 81-101.

${ }^{18}$ Bodansky H, Cudworth A, Drury P, Kohner E: Risk factors associated with severe proliferative retinopathy in insulin-dependent diabetes melitus. Diabetes Care 1982, 5: 97100.

${ }^{19}$ Bradley R, Rames E: The eyes and diabetes. In: Marble A, White P, Bradley R, eds. Joslin's Diabetes Mellitus. 11th Edition. Philadelphia: Lea \& Febiger, 1971, 485.

20) Engerman R, Kern T: Progression of incipient diabetic retinopathy during good glycaemic control. Diabetes 1984, 33: 9-100.

${ }^{21}$ Bodanski H, Cudworth A, Whitelock R: Diabetic retinopathy and its relationship to type of diabetes: A review of a retinal clinic population. Br J Ophthalmol 1982, 66: 496-9. 